\title{
The fate of received sperm in the reproductive tract of a hermaphroditic snail and its implications for fertilisation
}

\author{
Joris M. Koene · Kora Montagne-Wajer • \\ Dick Roelofs · Andries Ter Maat
}

Received: 5 November 2007/ Accepted: 5 March 2008/Published online: 20 March 2008

(C) Springer Science+Business Media B.V. 2008

\begin{abstract}
Multiple mating, sperm storage and internal fertilisation enhance sperm competition. The great pond snail can use stored sperm for over three months, and frequently mates with different partners. This hermaphrodite, Lymnaea stagnalis, can also selffertilise and often produces egg masses containing both selfed and outcrossed eggs. Hence, a sperm recipient may exert considerable control over paternity. Using microsatellite markers, we show that when allosperm are present, all genotyped eggs are cross-fertilised. We also find that sperm have the opportunity to compete, because double matings lead on average to equal paternity for each sperm donor. This indicates that received sperm are randomly mixed in storage. To gain further insight into the mechanisms underlying the process of sperm storage, digestion and utilisation, we investigated the fate of donated sperm at different times after copulation. We find that within $3 \mathrm{~h}$ after transfer most sperm have been transported into the sperm-digesting organ. Fluorescent labelling of sperm in histological sections further reveals that allosperm are not stored in the fertilisation pouch, but upstream in either the hermaphroditic duct, seminal vesicles, or ovotestis. Besides contributing to the understanding of the mechanisms underlying sperm competition and/or cryptic sperm choice, this study shows that mixed mating cannot be treated as a separate issue in hermaphroditic animals.
\end{abstract}

J. M. Koene $(\bowtie) \cdot$ K. Montagne-Wajer $\cdot$ D. Roelofs $\cdot$ A. Ter Maat

Department of Animal Ecology, Faculty of Earth and Life Sciences, VU University,

De Boelelaan 1085, 1081 HV Amsterdam, The Netherlands

e-mail: joris.koene@falw.vu.nl

K. Montagne-Wajer

e-mail: kora.montagne.wajer@falw.vu.nl

D. Roelofs

e-mail: dick.roelofs@falw.vu.nltermaat@orn.mpg.de

A. Ter Maat

Max-Planck-Institut für Ornithologie, Postfach 1564, 82305 Starnberg, Germany

e-mail: termaat@orn.mpg.de 
Keywords Gastropoda $\cdot$ Hermaphrodite $\cdot$ Mollusca $\cdot$ Outcrossing $\cdot$ Pulmonata ·

Selfing

\section{Introduction}

Sperm competition has been defined as "the competition within a single female between the sperm from two or more males for the fertilisation of the ova" (Parker 1970). Thus, the presence of sperm from more than one male within a female is required, but this does not necessarily imply skewed sperm utilisation patterns (Simmons and Siva-Jothy 1998). Although studies on insects and birds predominate, sperm competition is currently accepted as ubiquitous in animals (reviewed in Smith 1984; Birkhead and Møller 1998; Simmons 2001) and has pollen competition as a parallel in plants (Delph and Havens 1998). The simultaneous presence of sperm or pollen from different donors also allows for cryptic female choice, which is notoriously difficult to disentangle from sperm competition (e.g. Eberhard 1996).

Despite the fact that many hermaphroditic animals have specialised sperm storage and digestion structures that enhance sperm competition and cryptic sperm choice (reviewed in Baur 1998; Michiels 1998), surprisingly few studies have investigated these processes in detail. Moreover, those studies that did mainly involved reciprocally-mating simultaneous hermaphrodites (e.g. Bojat et al. 2001; Rogers and Chase 2002; Beese et al. 2006). Even in those species the details of sperm storage, removal and digestion are only partly understood. Yet, understanding the details of the fate of received sperm (hereafter called allosperm) is pivotal for explaining how sexual selection, via sperm competition and cryptic sperm choice, shapes the evolution of the male and female reproductive morphology and physiology (see also Schärer et al. 2007).

The details of allosperm processing by a recipient may also be essential for understanding another life history trait of many simultaneous hermaphrodites, the mating system. Hermaphroditic animals are often able to self-fertilise as well as cross-fertilise, and sperm recipients may thus exert considerable control over which auto- and allosperm are used for fertilisation. There are many examples of populations showing mixed mating in the field, i.e. producing selfed or outcrossed offspring (e.g. Henry et al. 2005; Jokela et al. 2006). A few studies showed that individuals can also perform mixed fertilisation, i.e. producing selfed and outcrossed eggs within one egg mass (e.g. Cain 1956; Städler et al. 1993; Gow et al. 2005). There are theoretical considerations as to whether and when producing selfed and/or outcrossed offspring is a good strategy to adopt (Jarne et al. 1993; Jarne and Charlesworth 1993). Most importantly, outcrossing is generally predicted to be favoured when inbreeding depression is high and individual heterozygosity is important. Selfing is predicted to predominate when there are high costs for the male function or for mate searching, even though selfing may lead to a loss of heterozygosity (e.g. Jarne and Städler 1995; Jokela et al. 2006). Overall, the higher efficiency of gene transmission through selfing compared to outcrossing is thought to be counterbalanced by inbreeding depression (e.g. Meunier et al. 2004).

The abovementioned consequences of selfing and outcrossing usually constitute the basis for the hypotheses devised to explain the evolution of mixed-mating systems. Surprisingly, all of this seems to be done without consideration of the underlying mechanisms involved in allosperm receipt. For example, is the production of selfed and outcrossed eggs a passive process or actively controlled by the female function? Moreover, often the occurrence of selfed and outcrossed eggs within one egg batch has not been considered. Such issues probably remained unaddressed because of the predominance of experimental 
and theoretical investigations of such mixed-mating systems in plants. Clearly, there are essential differences. For example, plants do not copulate and can therefore often not avoid fertilisation by own pollen (they are at the mercy of pollination). But, perhaps most importantly for the case considered here, they cannot store pollen the way that animals can store allosperm; animals can often do so for a whole breeding season or even much longer. This results in essential differences between pollen competition and sperm competition that cannot be ignored when looking for explanations for the occurrence of the production of selfed and outcrossed offspring. Hence, in order to explain how hermaphroditic animals optimise offspring production through their female function, via sperm competition, cryptic sperm choice and mixed fertilisation, detailed knowledge about the allosperm storage process will be essential.

Upon closer inspection, there seems to be a near-complete lack of knowledge about how the production of mixed offspring might work mechanistically in hermaphroditic animals. Despite the many efforts to explain mixed mating in evolutionary terms, very few studies have delved into the functional aspects of such a system, even though this was already advocated more than a decade ago (Jarne et al. 1993). As a consequence, there is detailed knowledge about the behavioural aspects of sperm transfer and the outcome of insemination and sperm competition (in terms of paternity and mixed mating). But, surprisingly little is known about the processes that take place in between, that is, the mechanisms that determine which sperm are used for the fertilisation of eggs and whether this results in mixed fertilisation.

To address the above issues, we have looked at aspects of sperm digestion, storage and use in a unilaterally inseminating hermaphrodite that can self- and cross-fertilise, the great pond snail Lymnaea stagnalis (Pulmonata, Basommatophora, Lymnaeidae). This species lays eggs in masses that have been reported to contain both selfed and outcrossed offspring (Cain 1956). Although these snails are simultaneous hermaphrodites, they can only mate in one sexual role within one copulation (Koene and Ter Maat 2005). Received sperm can either be digested in the bursa copulatrix (e.g. Horstmann 1955; De Jong-Brink 1969; Rogers and Reeder 1987; Clelland et al. 2001) or be stored for fertilising eggs (Cain 1956). In Basommatophora, sperm storage allegedly occurs at the junction where the hermaphroditic duct divides into a male and female tract, called the carrefour region, and where the fertilisation pouch is located (De Jong-Brink 1984; Geraerts and Joosse 1984). We here investigated the functional aspects involved in the processing of allosperm in this species.

\section{Material and methods}

Animals

Specimens of the great pond snail L. stagnalis (L.) were obtained from our laboratory culture. For the experiments we started out with immature, virgin individuals which had a shell height that was $<17 \mathrm{~mm}$. These were all kept individually in perforated plastic jars in the same large tank with running low-copper water of $20^{\circ} \mathrm{C}$. They were each fed one disc of lettuce $\left(19.6 \mathrm{~cm}^{2}\right)$ per day.

\section{Microsatellites}

For the initial tests of microsatellite heterozygosity we randomly selected mature specimens from the breeding tanks. Tissue samples were taken from the foot for which animals 
were anaesthetised using approximately $2 \mathrm{ml}$ of $50 \mathrm{mM} \mathrm{MgCl}_{2}$. The experimental animals were then returned to their individual housing and left to recover. The tissue samples were frozen at $-80^{\circ} \mathrm{C}$. We genotyped the individuals for 12 different microsatellite loci. For this, the tissue was thawed on ice and total DNA was extracted and purified using the Wizard SV Genomic DNA purification system (Promega, Madison, WI, USA): $150 \mu \mathrm{l}$ of Nuclei Lysis Buffer and $2 \mu \mathrm{l}$ of proteinase $\mathrm{K}$ were added to each sample. After vortexing, the samples were incubated for $2-3 \mathrm{~h}$ at $60^{\circ} \mathrm{C}$. After grinding up the tissue with a pestle, $250 \mu \mathrm{l}$ of SV RNA Lysis buffer was mixed in. This was followed by centrifuging for $5 \mathrm{~min}$ at $14,000 \mathrm{rpm}$. The DNA-containing supernatant was purified using a spin column by washing with SV RNA Lysis buffer and $500 \mu$ wash buffer $(3 \times)$, each time spinning off for $30 \mathrm{~s}$ at $14,000 \mathrm{rpm}$ (with a final dry spin). The DNA was then dissolved by adding $100 \mu \mathrm{l}$ nuclease-free water and, after $5 \mathrm{~min}$, spun off for $1 \mathrm{~min}$ at $800 \mathrm{rpm}$. The dissolved DNA was stored at $-20^{\circ} \mathrm{C}$.

The microsatellites were amplified via PCR, using nine published primers (Knott et al. 2003; Accession codes AY225955-AY225963) and three unpublished primers (kindly provided by E. Knott and M. Puurtinen). It is important to note here that in the Knott et al. (2003) publication the reverse primers are displayed in $3^{\prime}-5^{\prime}$ direction rather than the conventional $5^{\prime}-3^{\prime}$ order. Microsatellites were amplified in $29 \mu 1$ reactions containing $10 \times$ PCR buffer (MRC Holland), $0.17 \mathrm{mM}$ dNTPs (Invitrogen), $0.125 \mathrm{U}$ Taq Polymerase (MRC Holland), $0.17 \mathrm{mM}$ of each primer, $5 \mu \mathrm{l}$ of the dissolved DNA, and distilled water. The following cycling profile was used: denaturation for $2 \mathrm{~min}$ at $94^{\circ} \mathrm{C}$, followed by 35 cycles of $40 \mathrm{~s}$ at $92^{\circ} \mathrm{C}, 40 \mathrm{~s}$ at $55^{\circ} \mathrm{C}$ and $30 \mathrm{~s}$ at $70^{\circ} \mathrm{C}$, and a final extension period of $1.5 \mathrm{~min}$ at $72^{\circ} \mathrm{C}$. To assess polymorphism we separated $14 \mu \mathrm{l}$ of each PCR product on Spreadex EL 600 gels with a 100 bp size marker (Promega) on each gel and stained the gels with SYBR Gold (Molecular Probes). In the animals from our laboratory culture we found three different alleles for microsatellite loci A16 (AY225956) and B4 (AY225959), while the other loci were monomorphic or had only two alleles. We chose to use only A16 and B4 for the subsequent paternity experiments.

\section{Paternity}

After having identified the microsatellite alleles of all the animals, we made combinations of individuals so that in subsequent paternity testing we could unequivocally attribute offspring to either of the parents based on either microsatellite A16 or B4.

We allowed focal animals to copulate with one partner (singly-inseminated) or two partners (doubly-inseminated). All matings were observed, during $8 \mathrm{~h}$ on the same day. As soon as these animals had received sperm from their partner, they were returned to their original jar from which any self-fertilised egg masses had been removed. One randomly chosen subset of animals was allowed to mate a second time with a different partner on the following day. Again, all matings were observed and as soon as these animals had received sperm, they were returned to their original jar.

During the following days, we verified daily for egg laying by the singly- and doublyinseminated animals (resp. $N=5$ and $N=8$ ). The first egg mass that was laid was collected and left to hatch in a separate closed container. After three weeks, when the hatchlings were approximately $2 \mathrm{~mm}$, we randomly selected 10 of the hatchlings from each egg mass and stored these separately at $-80^{\circ} \mathrm{C}$. Once all the animals had produced an egg mass, the hatchlings were thawed and DNA was extracted, using the whole animal, for genotyping loci A16 and B4. 


\section{Location of sperm}

To find out what happens with the received sperm in the hours following insemination, we paired 96 virgin animals and separated them immediately after the first unilateral insemination. From these 48 pairs, 33 sperm recipients were used for weight measurements and the remaining 15 for histological processing. For both procedures, the animals were randomly used at $0,3,6,24$ and $48 \mathrm{~h}$ post-copulation. As controls we used respectively seven and three unmated virgin animals. For the weight measurement we first measured the shell height with callipers, and determined the body weight of the animal. We removed the shell and carefully dissected out the bursa copulatrix. We then determined shell weight, wet weight, and bursa copulatrix weight. We used seven unmated virgins for comparison.

For histology, the complete female reproductive tract was dissected out and three unmated virgins were used for comparison. The gonadal tissue was fixed using Bouin fixative. After fixation, the tissue was embedded in paraffin. The serial sections of $7 \mu \mathrm{m}$ were deparafinated using xylene. The sections were then alternatingly stained with the standard HE method (haematoxylin and eosin) and overnight with Vectashield mounting medium with DAPI (Brunschwig Chemie H1200). The latter staining was used to visualise the highly-condensed DNA in the sperm heads. A naïve observer scored the presence of sperm in (the allosperm groove running along) the different female organs.

\section{Results}

\section{Microsatellite variability}

Because we used cultured animals for this study, we first determined allelic diversity and heterozygosity for 12 microsatellites. This screening revealed that two of these loci, A16 and B4 were variable enough for further use in paternity testing. Table 1 shows the number of alleles found for each of the loci as well as the expected and observed heterozygosities.

Table 1 Microsatellites screened for variability in the L. stagnalis population from the breeding facility

\begin{tabular}{lllrlr}
\hline Locus & Accession code & No. of alleles & $\mathrm{N}$ & $\mathrm{H}_{\mathrm{O}}$ & $\mathrm{H}_{\mathrm{E}}$ \\
\hline A102 & AY225957 & 1 & 21 & 0.00 & 0.00 \\
A112 & AY225958 & 1 & 12 & 0.00 & 0.00 \\
A113 & & 1 & 12 & 0.00 & 0.00 \\
A16 & AY225956 & 3 & 240 & 0.63 & 0.63 \\
A2 & AY225955 & 2 & 12 & 0.25 & 0.13 \\
A5 & & 1 & 12 & 0.00 & 0.00 \\
B117 & AY225961 & 2 & 12 & 0.17 & 0.08 \\
B19 & AY225960 & 1 & 12 & 0.00 & 0.00 \\
B4 & AY225959 & 3 & 115 & 0.69 & 0.61 \\
C4 & AY225962 & 2 & 21 & $0.90 *$ & 0.45 \\
D103 & & 1 & 12 & 0.00 & 0.00 \\
D5 & AY225963 & 1 & 12 & 0.00 & 0.00 \\
\hline
\end{tabular}

Locus name, accession code, number of found alleles, number of individuals $(\mathrm{N})$, observed and expected heterozygosity $\left(\mathrm{H}_{\mathrm{O}}\right.$ and $\left.\mathrm{H}_{\mathrm{E}}\right)$ are shown. The microsatellites without an accession code are unpublished. The asterisk indicates a significant deviation from the Hardy-Weinberg equilibrium 


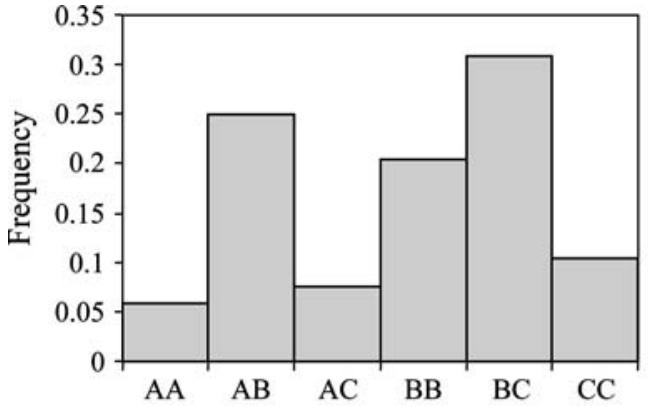

A16 Genotypes

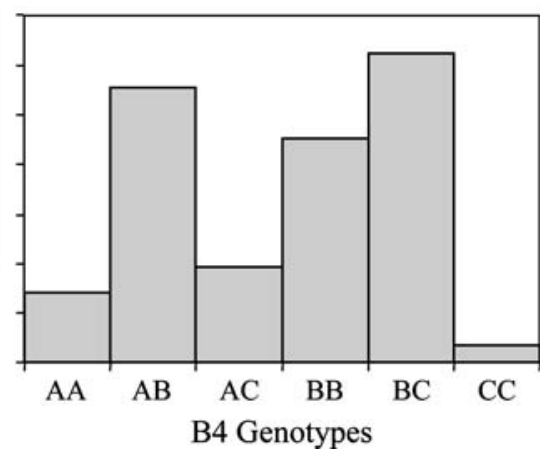

Fig. 1 Genotype distributions of microsatellite loci A16 and B4. The graphs show the frequencies of the different genotypes that were observed for $\mathrm{A} 16(N=240)$ and $\mathrm{B} 4(N=115)$. The alleles of each locus are labelled $\mathrm{A}, \mathrm{B}$ and $\mathrm{C}$ according to their length, from shortest to longest

For C4 the expected and observed frequencies differed significantly (Pearson $\chi^{2}=17.55$, $P<0.001$ ), and this locus thus deviated from the Hardy-Weinberg equilibrium. Figure 1 illustrates the distribution of the different genotypes for loci A16 and B4.

Paternity analyses

Because L. stagnalis can self-fertilise, we first tested whether they use the received sperm to fertilise their eggs. For the five virgins investigated, we found for each virgin that the 10 offspring analysed from their first egg mass after copulation contained only outcrossed eggs. Hence, although we only genotyped a proportion of each egg mass, the animals seemed to switch to complete outcrossing once sperm had been received. After having established this, we looked at patterns of paternity in focal virgins that copulated with two different partners (doubly-inseminated). Figure 2 shows the distribution of the $P_{2}$-values, i.e. the proportion of the offspring fathered by the second sperm donor. This revealed that in general sperm from both donors were used for fertilisation, with an average $P_{2}$-value of $0.6( \pm 0.28 \mathrm{SD}$; range $0.1-1.0)$. The second donor's paternity did not differ significantly from 0.5 (z-test: $z_{7}=1.01, P=0.31$ ).

\section{Location of sperm}

The average shell length at the end of the experiment of the animals was $3.06 \pm 0.08 \mathrm{~cm}$ and did not differ between the animals from the different time intervals (ANOVA: $\left.F_{5,34}=1.209, P=0.326\right)$. There was also no difference in body weight $(2.75 \pm 0.31 \mathrm{~g}$; ANOVA: $\left.\quad F_{5,34}=1.844, \quad P=0.130\right)$, shell weight $(0.41 \pm 0.06 \mathrm{~g} ; \quad$ ANOVA: $\left.F_{5,34}=1.991, P=0.105\right)$ and wet weight $\left(1.21 \pm 0.13 \mathrm{~g}\right.$; ANOVA: $F_{5,34}=1.718$, $P=0.157)$. The weight of the bursa copulatrix differed significantly among time intervals after copulation (ANOVA: $F_{5,34}=26.79, P<0.0001$; Fig. 3 ). This difference was entirely due to the $3 \mathrm{~h}$ group (post hoc Tukey: $P<0.05$ ). Thus, after $3 \mathrm{~h}$ most sperm were located in the bursa copulatrix.

Table 2 shows the organs within the female reproductive tract where fluorescentlylabelled sperm were found (in the allosperm groove). As indicated by the grey bars, (auto)sperm were always present in the hermaphroditic part of the reproductive tract (i.e. 
Fig. 2 Sperm of different donors fertilise eggs. Frequency distribution of the $P_{2}$-values, i.e. the proportion fathered by the second sperm donor, is shown for hatchlings from the first egg mass after a double insemination. The average $P_{2}$-value of 0.6 does not differ significantly from 0.5 ; the dotted line indicates the expected $P_{2}$ distribution if sperm mix randomly (see Results). Below the graph, the paternity of the offspring of each individual mother is ranked from high to low $P_{2}$-values. The grey bars represents the proportion fertilised by the second (2nd) father, which is also the $P_{2}$-value indicated on the $\mathrm{x}$-axis. The white bars represent the proportion fathered by the first (1st) father, $P_{1}$, which equals $1-P_{2} . N$ indicates the number of offspring analysed per mother

Fig. 3 Sperm digestion in the bursa copulatrix. The weights of the bursa copulatrix from unmated virgins and virgins at different times after one unilateral sperm receipt are shown. The box plots indicate median, 25th and 75th quartile, and range. Significant differences are indicated with different letters
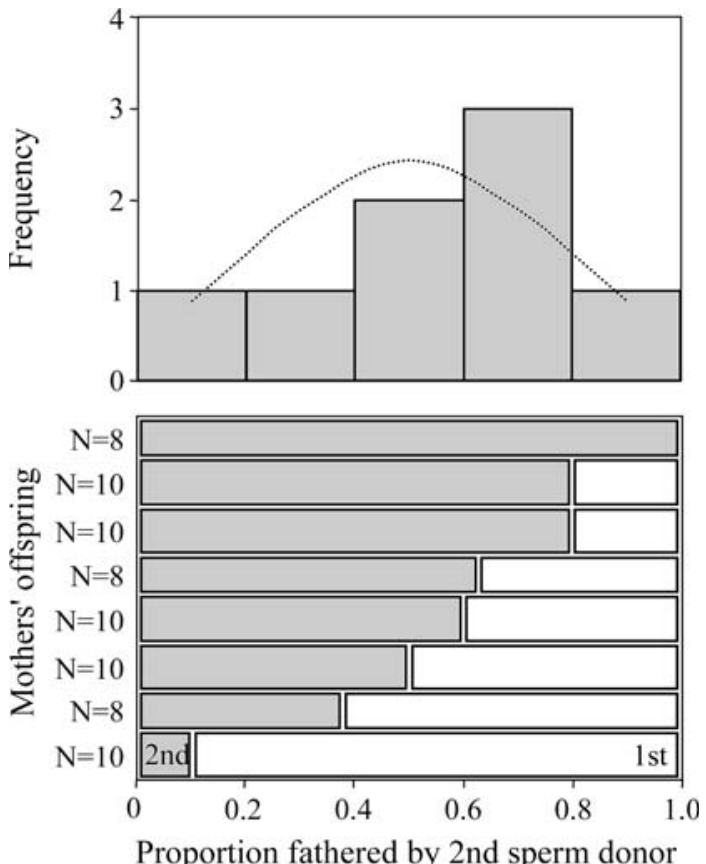

$\left(\mathrm{P}_{2}\right)$

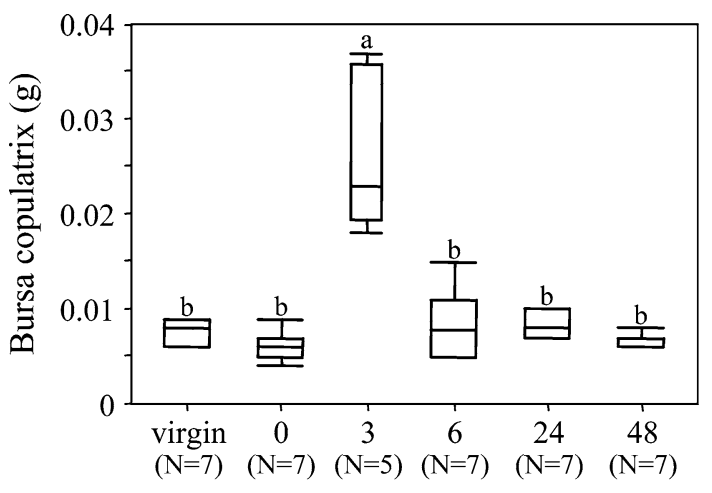

Time post-copulation (h)

ovotestis, seminal vesicles and hermaphroditic duct), also in unmated virgin snails. Immediately after copulation, the received sperm were present in the vaginal duct and the uterus duct leading up to the oothecal gland, which is consistent with previous findings (Loose and Koene 2008). At $3 \mathrm{~h}$ post copulation, sperm could be seen throughout the female tract, except for the vaginal duct. This was also the time when sperm were found in the fertilisation pouch. We also found this in one animal that was fixed after $6 \mathrm{~h}$ (as indicated by the lighter grey in Table 2). In the female tract of animals that were fixed after more than $6 \mathrm{~h}$, sperm were only found in the bursa copulatrix (besides the hermaphroditic parts). 
Table 2 Presence of sperm in the female reproductive tract of $L$. stagnalis at different intervals after copulation

\begin{tabular}{|l|c|c|c|c|c|c|c|c|c|c|}
\hline Post-copulation & OT & SV & HD & FP & PCO & MG & OG & BC & V \\
\hline No copulation (virgin) & & & & & & & & & & \\
\hline 0 hours & & & & & & & & & & \\
\hline 3 hours & & & & & & & & & \\
\hline 6 hours & & & & & & & & & \\
\hline 24 hours & & & & & & & & & \\
\hline 48 hours & & & & &
\end{tabular}

Grey indicates the presence of fluorescently-labelled sperm in the histological sections made at different times after copulation. The dark grey indicates that sperm were present in all of the three individuals fixed at that time interval, while the light grey indicates that sperm were only observed in one of the three individuals. Hence, sperm were only seen in the fertilisation pouch after $3 \mathrm{~h}$ (all three) and $6 \mathrm{~h}$ (one of three). The organs are listed from left to right in the anterior to posterior order as they are found in the reproductive system and the arrows indicate their locations in the schematic line drawing. Abbreviations: OT, ovotestis; SV, seminal vesicles; HD, hermaphroditic duct; FP, fertilisation pouch/carrefour; PCO, pars contorta; MG, muciparous gland; OG, oothecal gland; $\mathrm{BC}$, bursa copulatrix; V, vagina

\section{Discussion}

There seems to be a gap in our basic knowledge about sperm receipt in hermaphrodites that is essential for the understanding of sperm competition, cryptic sperm choice, and mixed mating. We have here looked at the fate of received sperm after transfer in the unilaterallyinseminating hermaphroditic pond snail L. stagnalis. We find that receipt of a single ejaculate by a virgin snail results in the first egg mass being completely composed of outcrossed offspring. More importantly, sperm of two donors are stored and both fertilise eggs within an egg mass, which results in a roughly equal share of paternity with rather large variance.

Thus, although the majority of the sperm will be digested (see below), some sperm do get stored. As a result, virgin animals switch to complete outcrossing right after sperm receipt. This is in stark contrast with the mix of selfed and outcrossed offspring that is usually found in population studies (e.g. Puurtinen et al. 2004). To properly understand such patterns, in a future study we plan to investigate allosperm use in subsequent egg masses. The result of the double matings does, however, reveal something essential about how sperm storage works in these animals. Namely, we find that both donors fathered offspring despite a $24 \mathrm{~h}$ inter-mating interval. Besides confirming that there is opportunity for sperm competition and cryptic sperm choice, the sperm precedence pattern strongly suggests that sperm of the two donors are well mixed before fertilisation (Harvey and Parker 2000). It has been argued that at such intermediate $P_{2}$-values sperm competition will be at its strongest, while highly skewed sperm utilisation patterns can indicate, for instance, non-random sperm mixing or cryptic sperm choice (e.g. Simmons and Siva-Jothy 1998; Simmons 2001). 
Our paternity data show that received sperm of two partners are both used and stored. The latter confirms previous observations (e.g. Cain 1956). Our histological data and bursa copulatrix weights indicate that within $6 \mathrm{~h}$ the received sperm have either reached the sperm storage site or the bursa copulatrix. Not unexpectedly, we find that received excess sperm get transported into the bursa copulatrix, the gametolytic organ, although initially received sperm were found throughout the female tract. The bulk of the sperm already reaches the bursa copulatrix within the first $3 \mathrm{~h}$ after copulation. And within the following hours, the digestive process greatly reduced its volume, as becomes apparent from the weight measurements. If the weight is representative of the digestive process, this would suggest that most of the sperm are digested within $6 \mathrm{~h}$ after the end of insemination. This clearly limits the time window within which sperm can reach the site of storage. Moreover, the quick reduction in weight also argues against a possible inhibition of remating via stretch receptors in the bursa copulatrix. This was previously suggested based on the presence of nervous innervation of this organ by a branch of the intestinal nerve (Elo 1938; Koene 2006), which is also important for egg laying behaviour (Ferguson et al. 1993). Although the volume of the bursa copulatrix could be registered via this nerve for some other purpose, it is unlikely that it serves to inhibit remating like it does in the cabbage white butterfly (Pieris rapae crucivora: Sugawara 1979).

It is noteworthy that we find no evidence that sperm are stored in the fertilisation pouch, which is confusingly-enough sometimes also labelled as receptaculum seminis. For $L$. stagnalis, and Basommatophora in general, sperm storage has long been assumed to occur in the fertilisation pouch (De Jong-Brink 1984; Geraerts and Joosse 1984). However, a closer look at the literature reveals that this suggestion is not based on direct evidence, but rather on an extrapolation from the situation in Stylommatophora where a well-defined allosperm storage organ is attached to their fertilisation pouch (spermathecal tubules; e.g. Duncan 1975). Tomé and Ribeiro (1998) also did not find any evidence for sperm storage in the carrefour region of the freshwater snail Biomphalaria tenagophila. Moreover, previous work on L. stagnalis also indicates that the fertilisation pouch is not suited for allosperm storage but the most likely site where fertilisation can ultimately take place before egg packaging starts (Plesch et al. 1971).

Allosperm cannot be stored downstream from the fertilisation pouch, because past that point the female glands are all involved in provisioning and packaging of the alreadyfertilised eggs. Hence, the three possible upstream sites for allosperm storage are the ovotestis, seminal vesicles and hermaphroditic duct. The ovotestis, where the own sperm and eggs are produced, has been put forward by two studies using radiolabelled sperm (Lobato Paraense 1976; Monteiro and Kawano 2000). However, given the time interval between copulation and detection of the label that those studies used (resp. 5 days and $6 \mathrm{~h}$ to 41 days) and the rapid sperm digestion that we find (within $6 \mathrm{~h}$ ), this idea requires reevaluation. The seminal vesicles have not been proposed before, even though they store the ripe autosperm and are thus specialised for this function. Of course, storage in these vesicles would complicate the separation of auto- and allosperm. Since there is no indication for separate compartments here, this would indicate that the priority of allosperm in the fertilisation process must be due to a difference in activation and/or capacitation of auto- and allosperm. The hermaphroditic duct has been suggested for allosperm storage by Larambergue (1939) and Bretschneider (1948).

In sum, although Cain already showed in 1956 that sperm can be stored and used for fertilisation for a long time in this species, the precise site of sperm storage remains elusive. Based on the foregoing and the data presented here, we can now narrow the potential storage sites down to the hermaphroditic duct, the seminal vesicles, and possibly 
the ovotestis. With the method we used here, we could unfortunately not distinguish autosperm from allosperm, so clearly this calls for an approach in which the sperm can be traced back individually after transfer (which seems now available: Schärer et al. 2004, 2007).

Revealing the exact site of allosperm storage will clearly provide novel insights into how mixed fertilisation and sperm competition work in this species. If allo- and autosperm are stored in the same site - the seminal vesicles or ovotestis - this might suggest that these animals have little control over which sperm fertilise eggs. Although it is of course still possible that these animals can control paternity through cryptic sperm choice, for instance via physiological or biochemical recognition of sperm. Separate storage-in the hermaphroditic duct-would imply more and easier control over selfing and outcrossing, and might best explain the complete outcrossing that we find here after one mating. Evidently, sperm competition, cryptic sperm choice and mixed mating can therefore not be treated as separate issues in these simultaneous hermaphrodites, but might be intricately entangled at the level of sperm receipt and storage.

Acknowledgements We thank C. Popelier for technical assistance; M.J. Loose, J.N.A. Hoffer, J. Ellers and N.M. van Straalen for fruitful discussions and valuable comments. JMK is supported by the Research Council for Earth and Life Sciences (ALW-NWO).

\section{References}

Baur B (1998) Sperm competition in molluscs. In: Birkhead TR, Møller AP (eds) Sperm competition and sexual selection. Academic Press, London, pp 255-306

Beese K, Beier K, Baur B (2006) Coevolution of male and female reproductive traits in a simultaneously hermaphroditic land snail. J Evol Biol 19:410-418

Birkhead TR, Møller AP (1998) Sperm competition and sexual selection. Academic Press, London

Bojat NC, Sauder U, Haase M (2001) The spermathecal epithelium, sperm and their interactions in the hermaphroditic land snail Arianta arbustorum (Pulmonata, Stylommatophora). Zoomorphology 120:149-157

Bretschneider LH (1948) Insemination in Limnaea stagnalis L. Proc Kon Ned Akad Wetensch 51:358-363

Cain GL (1956) Studies on cross-fertilization and self-fertilization in Lymnaea stagnalis appressa Say. Biol Bull 111:45-52

Clelland E, Di Renna T, Saleuddin ASM (2001) The structure of the bursa copulatrix in virgin and mated snails, Helisoma duryi (Mollusca): role of acid phosphatase in reproduction. Invert Biol 120:1-12

De Jong-Brink M (1969) Histochemical and electron microscope observations on the reproductive tract of Biomphalaria glabrata (Australorbis glabratus), intermediate host of Schistosoma mansoni. Z Zellforsch 102:507-542

De Jong-Brink M (1984) The regulation of male activity in the gonad of the hermaphrodite basommatophoran snail Lymnaea stagnalis. Adv Invert Reprod 3:213-222

Delph JF, Havens K (1998) Pollen competition in flowering plants. In: Birkhead TR, Møller AP (eds) Sperm competition and sexual selection. Academic Press, London, pp 149-173

Duncan CJ (1975) Reproduction. In: Fretter V, Peake J (eds) Pulmonates. Academic Press, London, pp 309365

Eberhard WG (1996) Female control: sexual selection by cryptic female choice. Princeton University Press, Princeton

Elo JE (1938) Das nervensytem von Lymnaea stagnalis (L). Lam Ann Zool Vanamo 6:1-40

Ferguson GP, Pieneman AW, Jansen RT, Ter Maat A (1993) Neuronal feedback in egg-laying behaviour of the pond snail Lymnaea stagnalis. J Exp Biol 178:251-259

Geraerts WPM, Joosse J (1984) Freshwater snails (Basommatophora). In: Tompa AS, Verdonk NH, Van den Biggelaar JAM (eds) The mollusca, vol 7, reproduction. Academic Press, New York, pp 141-207

Gow JL, Noble LR, Rollinson D, Tchuente L-AT, Jones CS (2005) High levels of selfing are revealed by a parent-offspring analysis of the medically important freshwater snail, Bulinus forskalii (Gastropoda: Pulmonata). J Mollusc Stud 71:175-180 
Harvey IF, Parker GA (2000) 'Sloppy' sperm mixing and intraspecific variation in sperm precedence $\left(P_{2}\right)$ patterns. Proc R Soc Lond B 267:2537-2542

Henry PY, Bousset L, Sourrouille P, Jarne P (2005) Partial selfing, ecological disturbance and reproductive assurance in an invasive freshwater snail. Heredity 95:428-436

Horstmann H-J (1955) Untersuchungen zur physiologie der begattung und befruchtung der schlammschnecke Lymnaea stagnalis L. Zoomorphology 44:222-268

Jarne P, Charlesworth D (1993) The evolution of the selfing rate in functionally hermaphrodite plants and animals. Annu Rev Ecol Syst 24:441-466

Jarne P, Städler T (1995) Population genetic structure and mating system evolution in freshwater pulmonates. Experimentia 51:482-497

Jarne P, Vianey-Liaud M, Delay B (1993) Selfing and outcrossing in hermaphrodite freshwater gastropods (Basommatophora): where, when and why. Biol J Linn Soc 49:99-125

Jokela J, Wiehn J, Kopp K (2006) Among- and within-population variation in outcrossing rate of a mixedmating freshwater snail. Heredity 97:275-282

Knott KE, Puurtinen M, Kaitala V (2003) Primers for nine microsatellite loci in the hermaphroditic snail Lymnaea stagnalis. Mol Ecol Notes 3:333-335

Koene JM (2006) Tales of two snails: Sexual selection and sexual conflict in Lymnaea stagnalis and Helix aspersa. Integr Comp Biol 46:419-429

Koene JM, Ter Maat A (2005) Sex role alternation in the simultaneously hermaphroditic pond snail Lymnaea stagnalis is determined by the availability of seminal fluid. Anim Behav 69:845-850

Larambergue MD (1939) Etude de l'autofécondation chez les gastéropodes pulmonés: recherches sur l'aphallie et la fécondation chez Bulinus (Isidora) contortus. Bull Biolog France et Belgique 73:19-231

Lobato Paraense W (1976) The sites of cross- and self-fertilization in planorbid snails. Rev Bras Biol 36:535-539

Loose MJ, Koene JM (2008) The effect of body weight, insemination duration and rearing condition on sperm transfer in a simultaneous hermaphrodite. Invert Biol (in press)

Meunier C, Hurtrez-Bousses S, Durand P, Rondelaud D, Renaud F (2004) Small effective population sizes in a widespread selfing species, Lymnaea truncatula (Gastropoda: Pulmonata). Mol Ecol 13:25352543

Michiels NK (1998) Mating conflicts and sperm competition in simultaneous hermaphrodites. In: Birkhead TR, Møller AP (eds) Sperm competition and sexual selection. Academic Press, London, pp 219-254

Monteiro W, Kawano T (2000) Location of allospermatozoa in the freshwater gastropod Biomphalaria tenagophila (d'Orbigny, 1,835) (Pulmonata; Planorbidae). Nautilus 114:74-79

Parker GA (1970) Sperm competition and its evolutionary consequences in the insects. Biol Rev 45:525-567

Plesch B, De Jong-Brink M, Boer HH (1971) Histological and histochemical observations on the reproductive tract of the hermaphrodite pond snail Lymnaea stagnalis (L). Neth J Zool 21:180-201

Puurtinen M, Knott KE, Suonpaa S, Van Ooik T, Kaitala V (2004) Genetic variability and drift load in populations of an aquatic snail. Evolution 58:749-756

Rogers D, Chase R (2002) Determinants of paternity in the garden snail Helix aspersa. Behav Ecol Sociobiol 52:289-295

Rogers SH, Reeder RL (1987) Structure and function of the spermatheca in a snail host of schistosomiasis, Biomphalaria glabrata. J Morph 191:295-308

Schärer L, Ladurner P, Rieger RM (2004) Bigger testes do work more: experimental evidence that testis size reflects testicular cell proliferation activity in the marine invertebrate, the free-living flatworm Macrostomum sp. Behav Ecol Sociobiol 56:420-425

Schärer L, Zaubzer J, Salvenmoser W, Seifarth C, Ladurner P (2007) Tracking sperm of a donor in a recipient: an immunocytochemical approach. Anim Biol 57:121-136

Simmons LW (2001) Sperm competition and its evolutionary consequences in the insects. University Press, Princeton

Simmons LW, Siva-Jothy MT (1998) Sperm competition in insects: mechanisms and the potential for selection. In: Birkhead TR, Møller AP (eds) Sperm competition and sexual selection. Academic Press, London, pp 341-434

Smith RL (1984) Sperm competition and the evolution of animal mating systems. Academic Press, Orlando

Städler T, Loew M, Streit B (1993) Genetic evidence for low outcrossing in polyploid freshwater snails (Ancylus flaviatilis). Proc R Soc Lond B 251:207-213

Sugawara T (1979) Stretch reception in the bursa copulatrix of the butterfly, Pieris rapae crucivora, and its role in behaviour. J Comp Physiol 130:191-199

Tomé LA, Ribeiro AF (1998) The functional organization of the carrefour in the reproductive tract of Biomphalaria temagophila (Mollusca, Planorbidae). Invert Reprod Develop 34:25-33 